\title{
Rak kot redek simptom sušice najmlajših borovih poganjkov
}

\section{Nikica OGRIS*}

Sušica najmlajših borovih poganjkov je najpogostejša in najnevarnejša bolezen borov v Sloveniji. Povzroča jo parazitska in kozmopolitska gliva Diplodia pinea (Desm.) J. Kickx f. (sinonim Sphaeropsis sapinea (Fr.) Dyko \& B. Sutton). Zajeda vse vrste borov; v Sloveniji sta najobčutljivejša črni bor (Pinus nigra Arnold) in rdeči bor (Pinus sylvestris L.). Diplodia pinea lahko v gostiteljih preživi kot parazit, saprofit in endofit. Posebej občutljivi so bori v stresu zaradi suše in pomanjkanja hranil.

Gliva pogosto povzroča odmiranje letošnjih poganjkov (od tod je bolezen dobila ime). Okuženi vršički poganjkov porjavijo in iglice na njih so krajše kot na zdravih poganjkih (slika 1). Odmiranje poganjkov spremlja smoljenje, ki ga opazimo v obliki številnih otrdelih smolnih kapljic na iglici ali skorji poganjkov. Navadno je odmiranje omejeno na propad enoletnega poganjka, ki še ni dokončno razvit. Enoletni poganjek lahko včasih odmre nekoliko kasneje, ko so iglice že normalne velikosti (slika 2). V tem primeru moramo biti pozorni, saj lahko podobno odmiranje povzročita vsaj še druga dva škodljiva organizma, npr. gliva Gremmeniella abietina (Lagerb.) M. Morelet, ki povzroča odmiranje poganjkov črnega bora, in gliva $\mathrm{Ce}$ nangium ferruginosum Fr., ki povzroča sušico borovih vej. Vse tri lahko razlikujemo po trosiščih: Diplodia pinea oblikuje temnorjave do črne kroglaste piknidije na iglicah, na osnovah iglic in skorji; Gremmeniella abietina tvori črne piknidije najpogosteje na odmrlih brstih; Cenangium ferruginosum oblikuje spolna trosišča - rjavo črne apotecije na skorji odmrlih poganjkov.

$\mathrm{V}$ izrazito sušnem in vročem vremenu lahko odmiranje zajame večletne poganjke in cele veje (slika 3 ). V takšnem primeru se odmiranje skorje razširi na celo drevo (slika 4). Čez nekaj mesecev porjavele iglice odpadejo in ostanejo samo gole veje (slika 5). Mlade odmrle iglice navadno ostanejo pritrjene še do dve leti, posivijo in na njih se razvijejo nespolna trosišča - piknidiji. Trosišča se pogosto razvijejo tudi na površini skorje, predvsem tam, kjer je ta tanka.
Sušica najmlajših borovih poganjkov redkeje povzroči razvoj raka na deblu. Ta redek simptom smo opazili na poškodovanem rdečem boru pri Jelšanah, 11. 6 . 2014 (koordinate Gauß Krüger $X=448.230$ m, $\mathrm{Y}=37.770 \mathrm{~m}$ ). Faza, ko se nekroza skorje širi iz veje v deblo navadno traja kratek čas, saj navadno hitro zaobjame cel obseg debla in posledično se prične sušiti ves predel krošnje, ki se nahaja nad odmrlim delom debla (slika 6). Če se odmiranje skorje upočasni, se na tem predelu debla lahko oblikuje rak, ki ima v središču odmrlo vejo in odmrlo skorjo v ovalni obliki (slika 7). Odmrla skorja in les pod njo sta močno prepojena $\mathrm{s}$ smolo (slika 8). Z glivo Diplodia pinea okužen les pomodri (slika 9), zato sušico najmlajših borovih poganjkov uvrščamo tudi med tehnične škodljivce lesa. Enak simptom, tj. rak na borih, lahko nastane zaradi borovega smolastega raka, ki ga povzroča karantenska gliva Gibberella circinata Nirenberg \& O'Donnell, ki jo v Sloveniji še niso ugotovili. Zato moramo vsako rakavo rano na borih preveriti in določiti povzročitelja. Za določitev borovega smolastega raka je s strani Uprave za varno hrano, veterinarstvo in varstvo rastlin pooblaščen Laboratorij za varstvo gozdov na Gozdarskem inštitutu Slovenije.

Opomba: Vse tukaj omenjene možne zamenjave s sušico najmlajših borovih poganjkov je mogoče ločiti na podlagi mikroskopskih morfoloških značilnosti trosišč, ki pa jih tukaj ne obravnavamo.

\section{Viri}

Butin H. 1995. Tree diseases and disorders. Causes, biology and control in forest and amenity trees. Oxford University Press: 252 str. Maček J. 2008. Gozdna fitopatologija. Ljubljana, Zavod za gozdove Slovenije, Zveza gozdarskih društev Slovenije - Gozdarska založba: 448 str.

*Gozdarski inštitut Slovenije, Večna pot 2, 1000 Ljubljana nikica.ogris@gozdis.si 


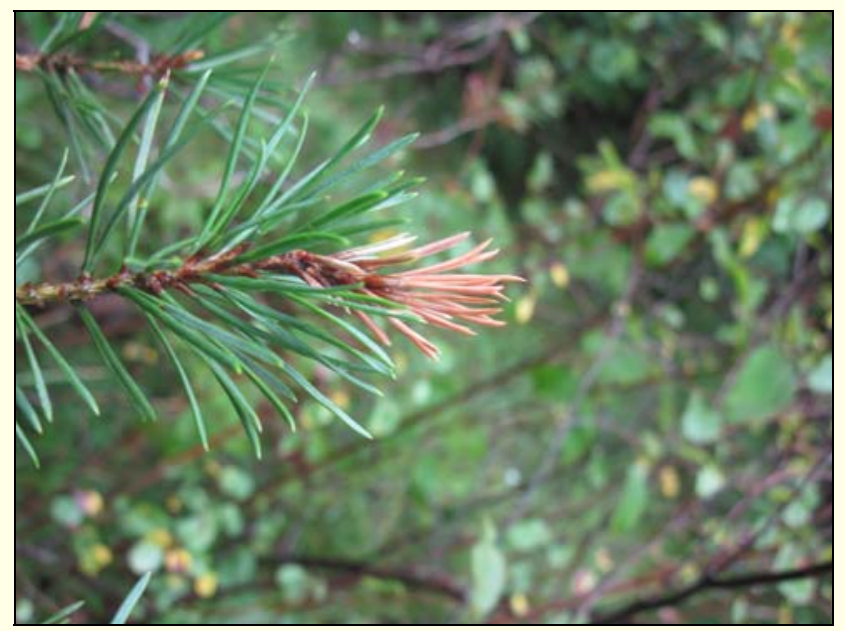

Slika 1: Vršiček poganjkov je porjavel, iglice so značilno krajše - najbolj značilen simptom sušice najmlajših borovih poganjkov (Foto. N. Ogris)

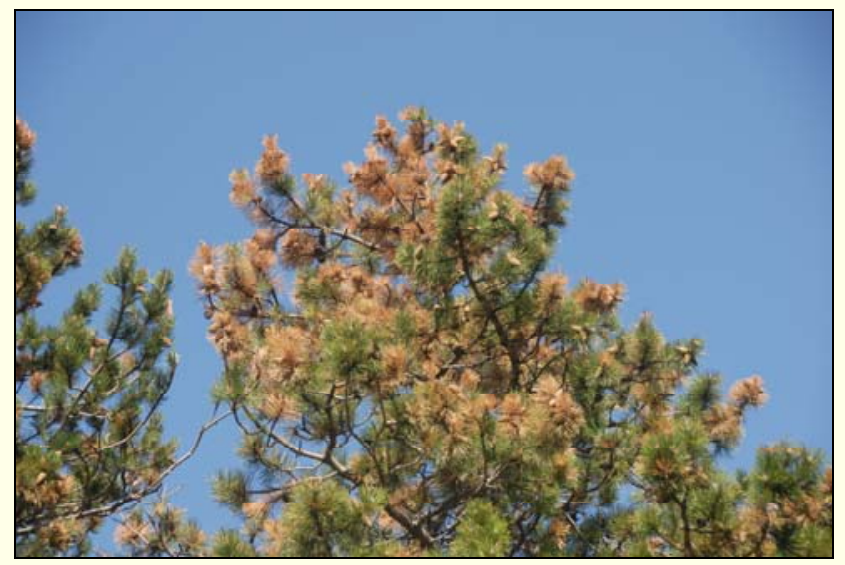

Slika 3: Odmiranje lahko zajame večletne poganjke in cele veje (foto: N. Ogris)

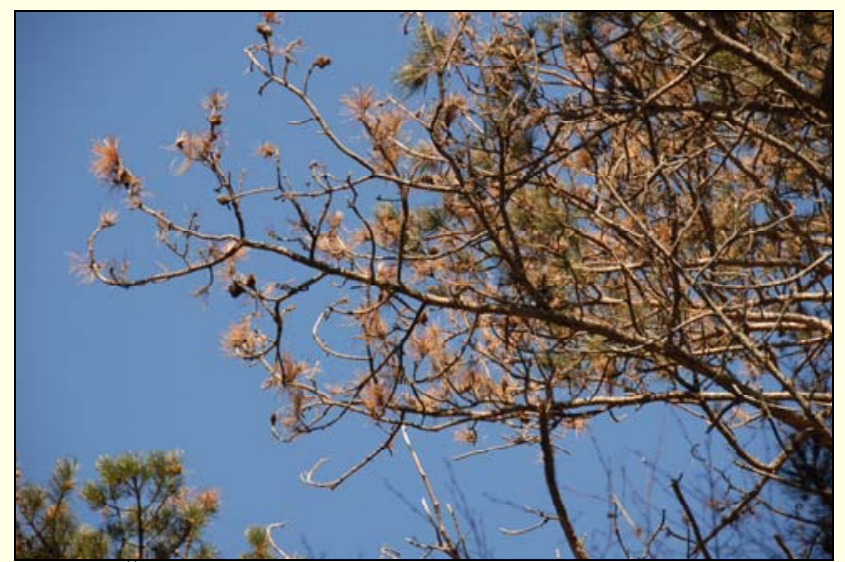

Slika 5: Čez nekaj mesecev rjave iglice odpadejo in ostanejo gole veje (foto: N. Ogris)

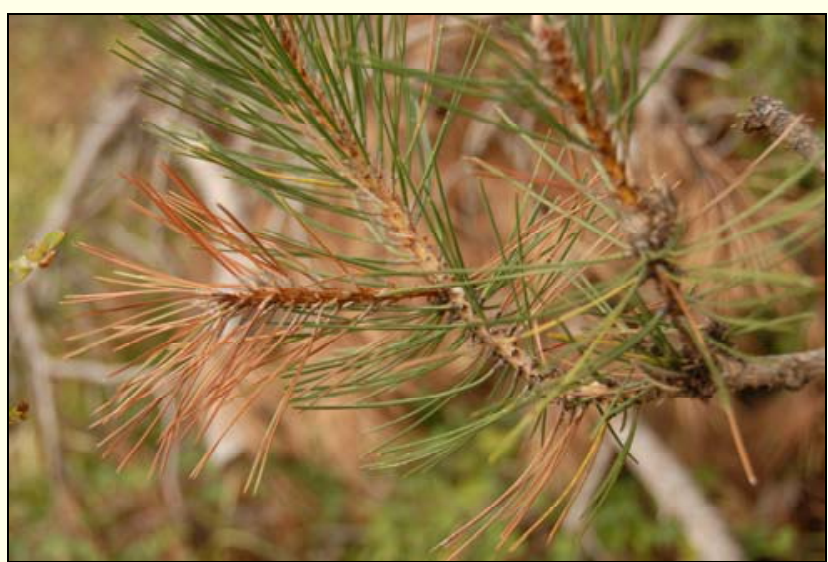

Slika 2: Posušil se je cel poganjek. Simptom lahko zamenjamo s poškodbami zaradi glive Gremmeniella abietina, ki povzroča odmiranje poganjkov črnega bora (foto: N. Ogris)

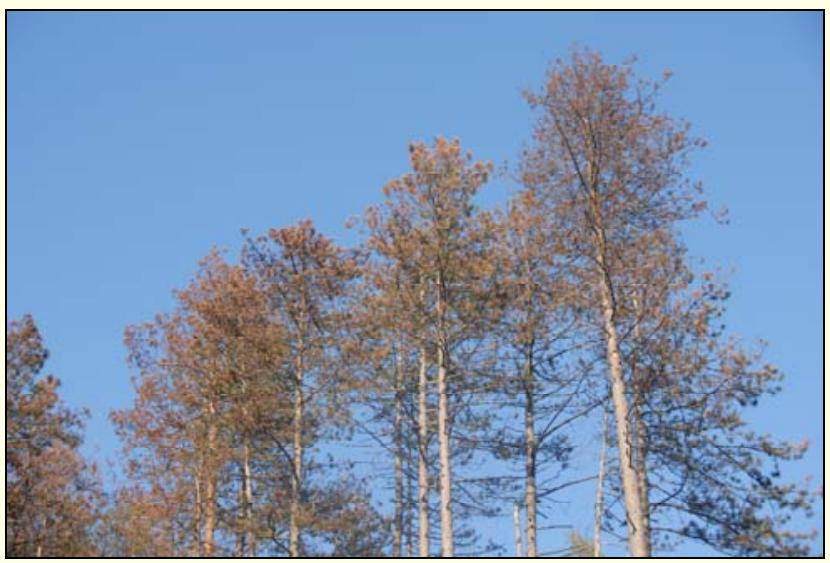

Slika 4: Odmre lahko cela krošnja in drevo (foto: N. Ogris)

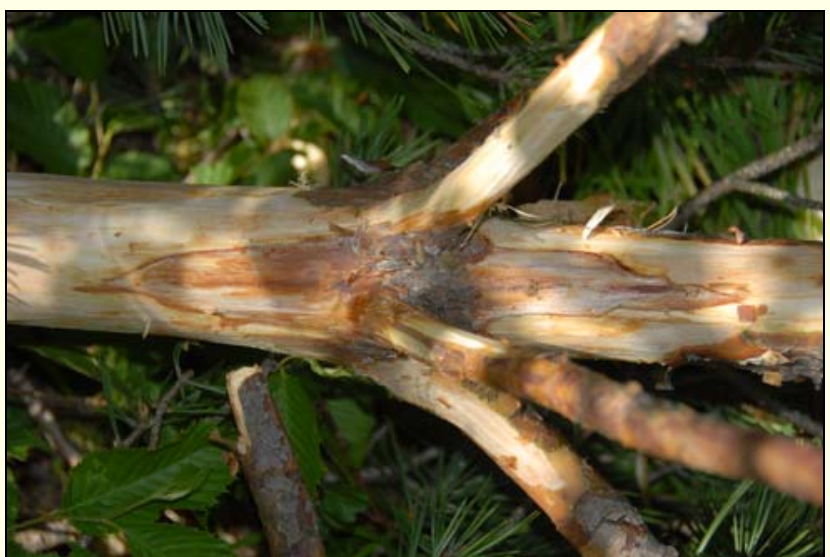

Slika 6: Redko lahko zasledimo fazo, ko se nekroza iz vej širi v deblo, saj je ta prehod navadno dokaj hiter (foto: N. Ogris) 


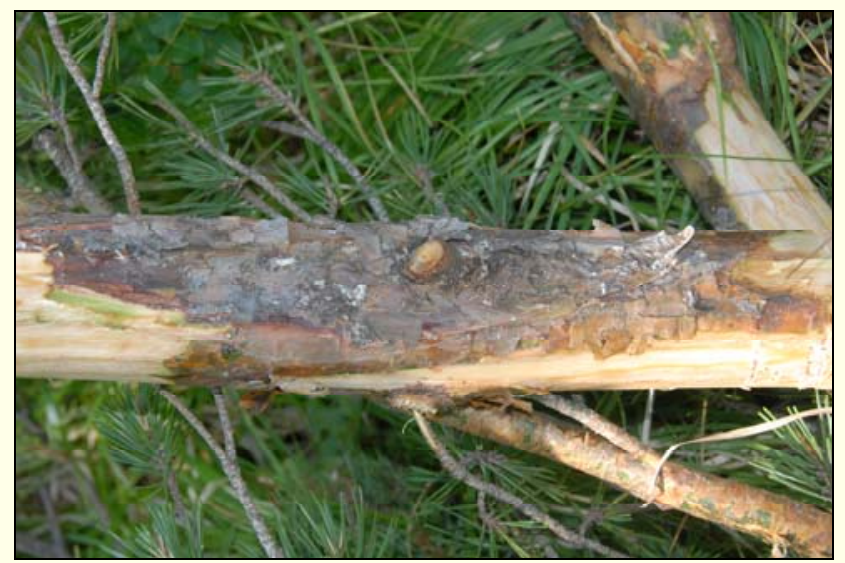

Slika 7: Sušica najmlajših borovih poganjkov redko oblikuje rakave rane (foto: N. Ogris)

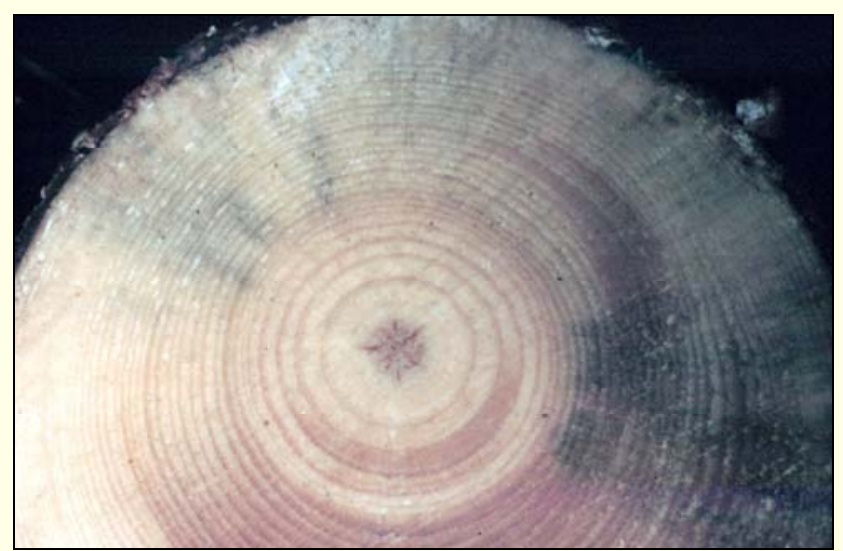

Slika 9: Diplodia pinea povzroča modrenje lesa (foto: D. Jurc)

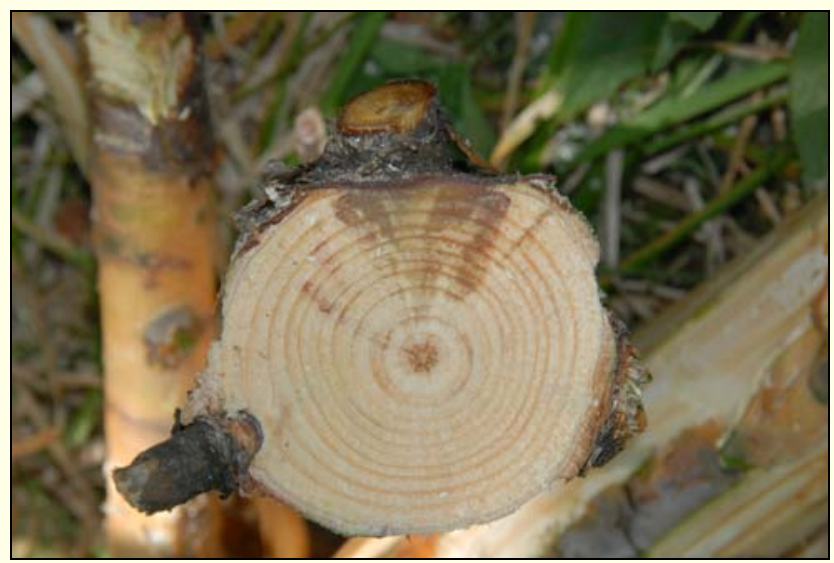

Slika 8: Odmrla skorja in les pod njo je prepojen s smolo (foto: N. Ogris) 